\title{
A Simple and Sensitive Electrochemical Sensor Based on Azodicarbonamide for the Determination of Tert- Butylhydroquinone in Food
}

\author{
Xinying Ma, Meifeng Chen, Shouqing Xue*, Huiping Lv, Qi Zhu, Fenghai Li \\ College of Chemistry and ChemicalEngineering of HezeUniversity, 2269 N. DaxueRoad, \\ Heze,Shandong, 274015,P.R.China. \\ *E-mail: hezexueyuanhx@163.com
}

doi: $10.20964 / 2020.03 .22$

Received: 10 November 2019/ Accepted: 19 December 2019 / Published: 10 February 2020

\begin{abstract}
An electrochemical sensor for the determination of the antioxidant tert-butyl hydroquinone (TBHQ) in food was prepared by using a modified electrode based onazodicarbonamide (ADC) on a glassy carbon electrode (GCE) surface. The electrochemical behavior of TBHQ on the modified electrode was studied by cyclic voltammetry (CV) and differential pulse voltammetry (DPV). The results showed that the peak redox current was significantly stronger than that on the bare GCE and that the detection sensitivity was improved. The experimental conditions, including the electrochemical polymerization $\mathrm{pH}$ value of the ADC solution, scanning rate, voltage, sweep segments and $\mathrm{pH}$ value of the TBHQ solution were optimized. Under optimal conditions, TBHQ presented a linear relationship with the oxidation peak current within the concentration range of $4.00 \times 10^{-7} \sim 4.00 \times 10^{-4} \mathrm{~mol} / \mathrm{L}$; the correlation coefficient was $\mathrm{R}=0.9988$, and the limit of detection was $1.80 \times 10^{-9} \mathrm{~mol} / \mathrm{L}$. The modified electrode was applied for the determination of real food samples containing TBHQ, with recovery ranging between 96.5 and $103.0 \%$. This electrochemical method showed good selectivity and high sensitivity.
\end{abstract}

Keywords: azodicarbonamide; glassy carbon electrode; tert-butyl hydroquinone

\section{FULL TEXT}

(C) 2020 The Authors. Published by ESG (www.electrochemsci.org). This article is an open access article distributed under the terms and conditions of the Creative Commons Attribution license (http://creativecommons.org/licenses/by/4.0/). 